\title{
Utilizing Undergraduate Assistants In General Education Courses
}

\author{
Michael W. Firmin, Cedarville University
}

\begin{abstract}
This conceptual article relates a best-practice paradigm for undergraduate faculty who teach relatively large, undergraduate, general education courses and utilize an undergraduate teaching assistant (TA). Suggested characteristics for successful TAs are related as well as intrinsic and extrinsic motivators that help recruit quality assistants. Five factors are shared that are believed to have made an undergraduate TA program successful for 20 years: the quality of students recruited, helping students to handle well their peer-relationships with students in the class, learning which items can and cannot successfully be delegated to TAs, harnessing the potency of relationships, and maintaining a healthy benefit/cost equilibrium with TAs.
\end{abstract}

Keywords: Teaching Assistant, TA, Undergraduate Teaching

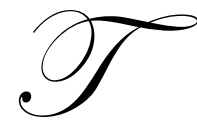

he complexities of differences in teaching undergraduate and graduate students are enormous. One salient difference is the focus on classroom instruction at the undergraduate level, particularly in large lecture classes (Katz \& Henry, 1993). General education courses frequently entail such mediums and may be encouraged by the administration, due to cost saving, and other similar benefits to the institution. It is simple math that paying multiple professors to teach smaller sized classes is far more expensive than hiring one professor to teach students en masse.

Smith et al. (1992) state that utilizing TAs has become an embedded part of American higher education, beginning with the founding of Johns Hopkins University in the German research university tradition. To the idealists, large universities which typically offer both graduate and undergraduate degrees, provide a mutuallybeneficial arrangement relative to the teaching-learning process. Namely, graduate students as TAs have the benefit of learning the teaching trade early in their professional careers (Boeher \& Sarkisian, 1985) which eventually makes them better classroom instructors in the long-run as they will someday assume full-time faculty teaching positions after earning their doctorates.

In exchange for tuition remission and other benefits, graduate students serve as Teaching Assistants (TAs) under the supervisory guidance of Ph.D. faculty. Freshmen courses or labs often are taught by TAs and most graduate programs view this as developmentally beneficial to the graduate students, as many will become professors after earning their graduate degrees. The TA experience, therefore, becomes somewhat of a learning laboratory for budding young faculty-in-the-making (Hoebusch, 2004).

Paulsen and Feldman (1995) believe that the milieu is quite different, however, for colleges and universities whose institutional missions focus solely or mostly on undergraduate education. Without the benefit of Ph.D. students to serve as TAs, such institutions are left to have doctoral or at least master's-level instructors in each course. Some liberal arts institutions market themselves as providing superior education to the large universities for this very reason - each course at the institution is taught by a Ph.D. As parents consider cost and other related factors for sending their children to various institutions, the matter of how many Teaching Assistants their children will have for the tuition dollars spent is a cogent selling point for private, undergraduate institutions. In other words, parents and students as consumers pay for student learning and Fink (2003) and Germano (2003) argue that they have a right to the best instruction money can buy. 
The present article is designed to be somewhat of a segue between these two milieu. That is, it is geared for faculty at primarily undergraduate institutions, but addresses the TA phenomenon in that setting. In short, can TAs be utilized in some manner, albeit not in the traditional sense of graduate students who are often primary instructors for freshmen-level courses? The authors own teaching experience has allowed him to successfully make some allowances in this domain. Specifically, he established an Undergraduate Student Assistant program and, although that formal title is used on paper-the students in class annually shorten this title to the letters TA which they seem to prefer.

This article is not intended to be an outcomes assessment of the program. Rather, it is a best-practice conceptual paper, sharing how the author operated this program and the experience he encountered with it. As a backdrop, the institution has about 3,000 students and is a private, comprehensive university. The average ACT is around 26, with most students majoring in professional (e.g., engineering, nursing, business, etc.) rather than traditional liberal arts majors. The author has been teaching psychology full-time for 20 years. In this context, the paper is organized around five factors that are believed to have made the undergraduate TA program successful.

\section{THE QUALITY OF STUDENTS RECRUITED}

More than any other factor, the failure or success of the TA program rests on this variable. That is, it is essential to recruit sharp undergraduate TA students who have the natural qualities for assisting with class needs. There a degree of canalization which occurs where success is never assured - but it is relatively predictable. There is not one sole type of ideal candidate for the position. However, following are some of the types of qualities that seem most salient.

\section{High ACT/SAT Score}

The limitations of college entrance exam scores relative to both philosophical and practical student outcomes, including the chance of false negatives with minority and other students, are readily apparent. Nonetheless, when finding an ACT score of, say, 30 or higher, one can be reasonably certain that the student is intelligent. There are no false positives with college entrance exams. Note, however, that ACT/.SAT is not a cut-off criterion. The author has utilized students for TAs with average scores and many have been successful. But possessing a strong college entrance score, everything else being equal with the other candidates, gives some students an edge for the two or three positions open each semester.

\section{Grade Point Average}

In the same way that there should not be an ACT criterion, students also should not be excluded based on their GPA. In fact, there have been some very good TAs who started as pre-med majors and did not do well their first couple of years in college. When they changed their major to psychology — these students' grades flourished. However, the GPA number on their transcript was relatively dismal.

When seeing a strong GPA, sometimes this marks people who work hard. That is, they are diligent and focused on academics. It sometimes is helpful to view students' psychology GPA since they will be a TA for the General Psychology course.

\section{Self-Motivated Applications}

Sometimes students who seemingly will make excellent undergraduate TAs are approached directly. However, in most cases students seek-out the position. Paying attention to students who are highly motivated for the role and show some assertion in making an appointment to talk about potentially being a TA is noteworthy. Generally, such ambition and motivation bode well for students when the job becomes tough and TAs may be tempted to bail out of the program. 


\section{Informal Recommendations}

The operative word here is informal. Most often it does not seem prudent to have students request formal letters when applying for the TA position. Generally, the types of people considered have two or three professors who admire them enough to write strong letters. In fact, almost anyone could find two or three people who would say good things about them if asked.

Consequently, informal recommendations are more profitable for obtaining the information most useful for this purpose. For example, asking previous TAs what they think about particular students can be insightful. Since former TAs know what the position entails, often they are good judges as to how well prospective candidates will fit the position. Also, querying particular respectable is helpful. Giving weighted counsel to these students is advised, more so than a formal letter of reference by someone who may have a dual-relationship with the student in question.

\section{Potential For Doctoral Studies}

With 160 psychology majors, the competition for two TA positions per semester often is keen. There are many years when good students desire the slot but there are not enough places to offer. Consequently, when I have multiple students of high quality - preference goes to those who are serious about perusing doctoral degrees. In my particular field, one must earn a doctorate in order to become a licensed psychologist and a master's degree in order to become a licensed professional counselor (LPC). In that light, perusing graduate studies is an important next step for psychology majors after completing their BA degrees.

Since many universities require General Psychology as part of the general education or liberal arts core, often there are plentiful TA positions for Ph.D. students in clinical or counseling psychology. Frankly, landing such a position is a great means for working one's way through graduate school. Ambitious psychology majors understand this, and typically they consider landing a graduate TA position as a plum.

Consequently, give special consideration to undergraduate students who will be applying to doctoral programs during their senior year of college. Having a successful experience at the undergraduate level helps them immensely when they compete for the graduate T.A. positions. In short, while pursuit of a doctoral degree is not a requisite for my undergraduate TA position, it does put a person first in line when I am considering multiple, talented and high-quality students for only a few open slots.

\section{Potential For The Future Professorate}

Since becoming a psychologist requires a doctorate, often there is a line of potential candidates for the undergraduate TA positions - and they all are quality students - and all have plans to pursue doctoral studies. Triage at this point tends to involve identifying those future Ph.D. students who wish to become college or university professors.

Some students wish to become psychologist practitioners. This is a wonderful and noble calling. However, in theory such persons will profit less (they will profit) from the TA experience than will a person who plans to someday make a career of college instruction. The latter student will take what they learn from my undergraduate TA program and someday, hopefully, become a better classroom instructor as a result. The future practitioner, in contrast, has less direct transfer of learning to counseling or clinical settings.

Since recruiting quality students is paramount for the success of the TA program, it follows naturally to ask the question: What motivates these students to volunteer for the program? Intrinsically, they seem to desire a mentoring relationship with me. That is, they enjoy the individual time that I spend with them and the inside-track to professorial life they can have as a result of our connectedness.

There also is a degree of prestige involved with being a TA. Most of the psychology majors are aware of who the TAs are each semester and there is a certain aura attached with the position. Past TAs have set an 
impressive track record of finding admission into the graduate schools of their choices which also adds to the mystique of what an undergraduate TA position could do for students' futures.

Students like the TA title. The phrase, "Undergraduate Student Assistant," never sticks and I have given up on trying to use it in class on a daily basis. There is something attractive about the two letters "TA" and the impression that it portrays.

A final intrinsic motivator is obtaining an inside peak at the university itself. Students do not have access to confidential faculty information - but they do have a closer glimpse of the inner-workings of how things work. TAs annually relate that they enjoy being on the cusp of news that is being released. They like hearing the stories of how faculty are achieving tenure and other similar issues about which most of their peers are clueless or very little exposure.

There tend to be three extrinsic motivators to being an undergraduate TA at the present author's university. The first is that students sign-up for three semester hours of credit. There are learning activities that accompany the position as well as the developmental learning that occurs. Most students are very committed to the position and the modal grade earned for the course is an A.

Second, students are keenly aware that being an undergraduate TA is a plume for their curriculum vitae. In clinical psychology doctoral programs, some students face acceptance ratios of 300 applicants to five or six openings. In that type of fierce competition for doctoral slots, students understand that being an undergraduate TA increases their odds of acceptance into Ph.D. programs where they wish to attend.

Third, there are a few perks that come with the position. For example, TAs receive a key to the psychology building and have access to the office and research rooms. They can photocopy, print, and have other similar officerelated privileges. The TAs have round-the-clock access to the instructor or any other faculty or staff with whom they need to connect for class purposes. Office and one's personal library of books can be with TAs, helping them with information searches when they are stuck on projects. In sum, there are not a lot of perks with the positionbut students do seem to enjoy some of the small bonuses.

\section{STUDENTS NEED TO HANDLE WELL THEIR PEER-RELATIONSHIPS WITH STUDENTS IN CLASS}

A second major factor in making the TA experience a successful one relates to the associations that the TAs have with their peers. Essentially, being an undergraduate TA is one of authority. However, they are not faculty. At the same time, the TA is not a true peer of the students in the classroom. They need to learn the art of avoiding extremes of authoritarianism and being students' buddies. To help TAs with this balance, use the word pre-professional when raising this issue with them. Also, expect them to dress like a faculty member at our institution-which includes men wearing ties on class days. TAs should communicate a pre-professional (not haughty) demeanor and remind their cohorts that for 15 weeks, they are friendly to students in the class — but not their friend.

\section{LEARN WHICH ITEMS CAN AND CAN NOT BE SUCCESSFULLY DELEGATED TO TAS.}

When first utilizing a TA program, it is tempting to treat TAs like graduate assistants. This may be particularly true if the respective instructor was a TA/RA/GA in graduate school. However, in reality undergraduate student assistants are just that - they are not really TAs.

Undergraduates do not, by and large, have the maturity that typically is found in graduate students. This is not to speak critically of the undergraduates. They just lack the developmental maturity that they will acquire with time. There are decisions that they are not yet ready to make, there are responsibilities they can not yet handle, and their life perspectives tend to be more concrete than abstract when thinking through the complexities of decisionmaking at times. The key, of course, is to maximize the undergraduate TA's potentials - without crossing a very subjective line where they are given responsibilities that are truly beyond them. 
Following is a partial list of responsibilities that typically can be delegated to undergraduate TAs: Daily attendance taking, entering grades (including providing grade distributions for the class), holding group study sessions for the class prior to each test, tutoring students (especially those in the university transition program), calculating final grades, handling routine e-mail correspondence from students regarding house-keeping items, administering make-up tests, suggesting lists of test questions, and proctoring tests or films when the instructor is absent.

It is important to note that TAs attend class each period with students. They are able to do course grading (away from the students), read, or do other homework while the instructor lectures. But they are physically present in class.. This helps them know what the genre of class is like and it is very useful for reference when doing review sessions and tutoring.

\section{RELATIONSHIPS ARE POWERFUL}

A fourth factor in making the TA experience a successful one relates to the connections that form between the instructor and the TA. When cultivated, this dynamic can result in TAs who will go to unusual lengths in order to provide quality services. TAs sometimes stay up to wee hours at night, miss some of their other classes, quit outside employment, and take other self-sacrificing steps in order to do the best job they could as a TA. Note that an instructor should not be a slave driver and should not ask students to take this type of extreme action. But often they do - so setting reasonable boundaries is necessary at times. The point here is that when developing a close relationship with a TA, and if they highly respect the instructor and revere the position they hold - then the result can be very powerful. Do not overlook this dynamic.

\section{MAINTAIN A HEALTHY BENEFIT/COST EQUILIBRIUM WITH TAS}

For instructors teaching large general education classes, undergraduate TAs can provide relief from the burden of the mundane, but necessary tasks of college instruction. Since time and energy for any given course is finite, the TAs time enables the professor to focus on the more significant aspects of the class. For example, the instructor does not need personally to take attendance, or calculate grades. It is important to know attendance patterns for given students and how students are doing - but that information does not have to be obtained personally by the instructor. By delegating, the instructor is freed physically and psychologically to focus attention on quality instruction and matters most germane to effective education. Every minute on the stopwatch spent doing house-keeping matters for my class is a minute that I am not developing it to new levels of excellence.

Initially, this sounds like the TA position is all positive. However, in reality TAs also take time. The mentoring about which I spoke earlier - that is so meaningful and motivating to them - is also time consuming for me. If I am not careful, then I could potentially spend as much time mentoring TAs each day as the time I "save" via the tasks they perform in my behalf. Keeping this in balance is the point.

In addition, TAs screw-things-up at times. That is the nature of being a college student. At the semester's beginning an instructor should try to be exceptionally careful and cover all the details — but sooner or later - each semester-multiple times in the semester they will make mistakes. When they do, it generally costs the instructor time and energy. So long as these gaffes are kept to a reasonable level, then the trade-off is fine. However, if a TA needs too much supervision, or makes too many errors - then the benefit/liability scale is tipped in an unwanted direction for me. In sum, TAs are wonderful blessings, but they are also time expensive. When developing an undergraduate TA program, be sure to budget-in this cost and keep it such that the benefits received as a professor outweigh the natural hassles and time consuming agitations that will occur utilizing their assistance.

\section{REFERENCES}

1. Boehrer, J. \& Sarkisian, E. (1985). The teaching assistant's point of view. In Strengthening the Teaching Assistant Faculty. J.D. Andrews, editor. San Francisco: Jossey-Bass. 
2. Fink, L. D. (2003). Creating significant learning experiences: An integrated approach to designing college courses. San Francisco, CA: Jossey-Bass.

3. Germano, W. (November, 28, 2004). The scholarly lecture: How to stand and deliver. The Chronicle of Higher Education. p. B15.

4. Hoebusch, H. (November 2004). Beyond the portfolio: Project-based TA assessment. A paper presented at the $23^{\text {rd }}$ Annual Lilly Conference on College Teaching, Oxford, $\mathrm{OH}$.

5. Katz, J. \& Henry, M. (1993). Turning professors into teachers: A new approach to faculty development and student learning. Phoenix: The Oryz Press.

6. Paulsen, M. B. \& Feldman, K. A. (1995). Taking teaching seriously: Meeting the challenge of instructional improvement. Washington, D. C.: George Washington University.

7. Smith, R. M., Byrd, P., Nelson, G. L., Barrett, R. P., \& Constantinides, J. C. (1992). Crossing pedagogical oceans: International teaching assistants in U.S. undergraduate education. Washington, D.C.: George Washington University Press.

\section{NOTES}

